\title{
Demonios con entendimiento. Política y moral en la filosofía práctica de Kant
}

\section{Understading Devils. Politics and Morality in Kant's practical philosophy}

\author{
EFRAÍN LAZOS \\ IIF-UNAM, México
}

\begin{abstract}
Resumen. El ensayo estudia dos fuentes de tensión en la idea kantiana de sociedad: por un lado, la tensión configurada por las conexiones y diferencias entre la moral y la política; y, por otro, las tensiones entre dos relatos o líneas argumentales que dominan los textos kantianos, los relatos trascendental y teleológico. La propuesta del ensayo es que tales tensiones pueden atenuarse con un sesgo particular, esto es, enfatizando el relato trascendental y la tesis de la primacía de la moral, frente al relato teleológico y la tesis de la independencia de la política respecto de la moral.
\end{abstract}

Palabras clave: contrato original, demonios, deber, teleología.
Abstract. This essay studies two sources of tension within Kant's idea of society: on the one hand, the tension arising from the connections and differences between morality and politics; on the other, the tensions between two narratives or argument lines which dominate Kant's texts, the transcendental and the teleological narratives. The essay argues that such tensions may only be attenuated with a particular slant: that is, emphasizing the transcendental narrative and the thesis of the primacy of morality, over and above the teleological narrative and the thesis of the independence of politics vis a vis morality.

Key words: original contract, devils, duty, teleology.

0. Las reflexiones de Kant sobre la política gravitan alrededor de una preocupación teórica que, de una manera o de otra, él comparte con sus predecesores modernos tanto como con sus sucesores. ${ }^{1}$ Podría formularse como la preocupación por conciliar el máximo de libertad individual con el máximo

1 Lo que podría llamarse la filosofía política de Kant se halla entreverado con sus ideas sobre la historia, la moralidad, el derecho y la religión. Algunas de sus ideas sobre el orden político se encuentran en ensayos ocasionales relativamente cortos, mientras que otras forman parte de obras sistemáticas. Entre los primeros han de mencionarse la Idea para una historia universal en clave cosmopolita (1784), obra que inaugura la reflexión kantiana sobre la historia, así como Qué es la ilustración (1784), Teoría y práctica (1793) y Hacia la paz perpetua (1795); entre las segundas han de mencionarse la Crítica de la facultad de juzgar (1790), la Religión dentro de los límites de la mera razón (1793) y la Metafísica de las costumbres (1797). 
de orden social. Se trata, para Kant, del problema consistente en constituir un orden social justo. Desde el comienzo, éste es considerado «el problema más grande para especie humana», y a lo largo de sus trabajos políticos el filósofo se dedica a pensar, desde distintos ángulos, las características estructurales básicas de una sociedad de ciudadanos «que pueda administrar la justicia universalmente» (Idea, AA VIII, 22). Al resultado de ese ejercicio filosófico puede llamársele la idea de sociedad de Kant. Esta idea es propiamente una representación racional del orden social; posee un contenido normativo cuya validez es independiente de la experiencia - independiente de cómo esté de hecho constituida una sociedad dada - y tiene el carácter de un ideal trascendental, a la manera de un rasero que las sociedades nunca alcanzan, pero al que, sin embargo, deberían acercarse cada vez más, como en una asíntota.

1. No es de sorprender que la idea kantiana de sociedad esté recorrida por diversas tensiones internas. En este escrito me ocuparé de dos de ellas, las más aparentes, ambas mutuamente vinculadas. Dicho de modo preliminar, la primera tensión radica en al área de las diferencias y conexiones entre la moral y la política. La segunda tensión está constituida por dos relatos o, si se quiere, dos líneas argumentales, que se entremezclan en la idea de sociedad, los relatos que llamaré teleológico y trascendental. Antes de indicar cómo están vinculadas estas dos fuentes de tensión, hay que dar una caracterización más amplia de cada una de ellas. La primera está configurada por dos polos: en uno de ellos se encuentra la concepción, aparente en diversos pasajes de los escritos políticos de Kant, según la cual, en un estado justo, una persona moralmente mala puede ser un buen ciudadano (Arendt 1982, 17). En otros términos, la idea kantiana de la sociedad no requiere que los ciudadanos actúen según principios morales. Tal concepción está conectada con la relativa urgencia que le adjudica Kant al problema político, y tiene en su favor la sana noción de que los asuntos morales, los cuales conciernen al fuero interno de cada individuo, no son competencia de la autoridad política. Me referiré a tal idea como a la tesis de la independencia de la política respecto de la moral. En el otro polo se encuentra la concepción de que, en una sociedad racionalmente concebida, ser moralmente bueno basta para ser un buen ciudadano. Este polo de la tensión es la expresión de una clara tendencia, que también exhibe Kant en sus escritos, hacia la moralización de la política; en el límite, ahí donde difieran los fines de la política y los de la moralidad, ahí deben sacrificarse los primeros ante los segundos - algo así como la política dentro de los límites de la mera razón práctica. Me referiré a esta idea como a la tesis de la primacía de la moral respecto de la política. Ambas ideas parecen valiosas, y cada una de ellas resulta aceptable, al menos intuitivamente, pero no son fácilmente conciliables (Yovel 1980, 21 y ss.).

El segundo factor de tensión radica en los dos relatos dominantes que se entremezclan y, al menos en apariencia, convergen en la idea kantiana de sociedad. Uno, el que emerge con mayor fuerza en los escritos sobre filosofía 
de la historia, señaladamente en la Idea de la historia en sentido cosmopolita y en Hacia la paz perpetua, es el relato teleológico, el cual entiende los acontecimientos humanos considerados «a gran escala», la historia de la especie humana, como un plan de la naturaleza cuyo propósito es erigir la concordia, o paz perpetua, a través de una constitución civil perfecta que garantice relaciones libres e igualitarias entre los individuos y entre los pueblos. El otro relato, más aparente en trabajos tales como Teoría y práctica y la Doctrina del derecho en la Metafísica de las costumbres, es el que podría denominarse «trascendental»; se trata de la variante política de una idea rectora de la filosofía crítica, a saber, que un mero agregado de elementos no constituye de suyo una unidad - en este caso Kant parte de que un mero conjunto de seres humanos cuyas relaciones están normadas por leyes positivas no constituye de suyo una sociedad de ciudadanos (bürgerliche Gesellschaft), y fundamentalmente se propone establecer las condiciones racionales en las cuales los seres humanos pueden coexistir libremente.

No es que ambos relatos entren en colisión directa. De hecho, Kant los presenta como complementarios. Según el relato teleológico, los acontecimientos humanos siguen un plan de la naturaleza para producir la concordia, incluso cuando los seres humanos no tengan el menor interés en lograrla - e incluso cuando, como en las guerras de todo tipo, se opongan activamente a ella. El relato trascendental se ocupa de establecer las condiciones no empíricas bajo las cuales la concordia es posible. Pero sucede que, como espero mostrar, cada relato procura una concepción distinta de los agentes que entran en concordia, con lo cual parece que, lejos de ser complementarios, conducen a resultados distintos. En particular llevan a maneras incompatibles de entender, e intentar resolver, las tensiones entre política y moralidad. Mi argumento será que dichas tensiones se resuelven $-\mathrm{y}$ en esa medida la idea kantiana de sociedad adquiere coherencia - sólo si se reinterpreta el relato teleológico, lo cual lleva, si no al rechazo de la tesis de la independencia, al menos a su reformulación.

2. Como es sabido, para exponer su idea de sociedad, Kant recurre al dispositivo del contrato original. No me detendré en discutir cómo se distingue el kantiano respecto de otros modelos históricos del contrato social, ni en qué sentido puede ser tildada la teoría kantiana de la sociedad como contractualista. Lo que me interesa es el papel que juega este dispositivo en su argumento general. El contrato original es, efectivamente, parte sustantiva de lo que hemos llamado el relato trascendental. Diré primero algo sobre la naturaleza del contrato original, tal y como lo entiende Kant; después abordaré el asunto del contenido del contrato, lo cual lleva obligadamente a considerar la idea kan- 
tiana del derecho. Conviene tener presente un pasaje clave al respecto, el párrafo inicial de la segunda parte de Teoría y práctica:

Entre todos los contratos por los que un conjunto de personas se unen para formar una sociedad (pactum sociale), el contrato que establece entre ellos una constitución civil (pactum unionem civilis) es de índole tan peculiar que, aunque desde el punto de vista de la ejecución tenga mucho en común con todos los demás (que están orientados a promover colectivamente un fin cualquiera), se diferencia esencialmente en el principio de su institución (constitutionis civilis). La unión de muchas personas en orden a cualquier fin (fin común, que todos tienen) se encuentra en todo contrato social; pero la unión de estas personas que es un fin en sí misma (fin que cada una debe tener), por tanto la unión de todas las relaciones externas, en general, entre las personas - que no pueden evitar influenciarse mutuamente-, es un deber primordial e incondicionado; tal unión sólo puede encontrarse en una sociedad en la medida en que ésta se halle en estado civil, esto es, en la medida en que constituye una cosa pública [ein gemeines Wesen]. (T\&P, AA VIII, 289)

Lo primero que destaca en esta presentación es que el contrato original no se refiere, ni siquiera en forma metafórica, a una situación histórica dada. Esto quiere decir que no se propone explicar ni justificar el presente social a partir de lo que, de hecho, ha pasado. Como lo sugiere el propio Kant con su característico sesgo utópico, el estado de cosas social que representa el contrato original no ocurre, no ha ocurrido y, presumiblemente, no ocurrirá nunca (MS § 61, AA VI, 350). Se trata de una suerte de experimento de pensamiento mediante el cual se busca determinar las condiciones de la concordia social independientemente de los fines que, de hecho, se hayan propuesto o se propongan los agentes particulares. Esto quiere decir que la idea kantiana de contrato responde a la pregunta por el quid juris de la concordia social - por las condiciones normativas de la condición civil de los humanos (Riedl 1981, 601). Esta manera de ver la naturaleza del contrato supone entonces que ninguna situación social de facto puede legitimarse por su origen - ni por su antigüedad, ni por su majestad o su santidad.

Como para explicar el carácter original del contrato, Kant indica en la Doctrina del Derecho que se trata de «el acto mediante el cual un pueblo [Volk] se constituye en Estado [Staat]», e inmediatamente agrega que es «sólo la idea» de ese acto; pero es una idea únicamente en términos de la cual «podemos pensar la legitimidad [Rechtmässigkeit] de un Estado» (MS § 47, AA VI, 315).

Veamos esto desde el ángulo del contenido del contrato. Como todo pacto, el contrato original está determinado por el objetivo o fin que se proponen los contratantes conseguir a través de la cooperación. En este caso lo que se pacta es una constitución ciudadana, un sistema de leyes que, como le gusta decir a Kant, garantice la paz perpetua, la concordia entre los individuos y los 
pueblos del mundo. Esto quiere decir que, si lo que normalmente lleva a la cooperación es el logro de un determinado fin, en el caso del contrato original, el fin del contrato es la cooperación por la cooperación misma. Es por eso que, si en cualquier otro tipo de contrato la cooperación depende del fin colectivo propuesto y dura tanto como el proceso mediante el cual se consigue colectivamente ese fin, en el caso del contrato original la cooperación se presenta como un deber incondicionado que se extiende indefinidamente a lo largo del tiempo. Es por eso que la concordia social buscada puede calificase como una condición de paz perpetua. Pero así como la paz perpetua no es sólo ausencia de guerra (un armisticio, un tratado de no agresión, una guerra fría), no cualquier situación de concordia entre los miembros de una comunidad - en el sentido de ausencia de conflicto- puede considerarse racionalmente aceptable. Harto sabía Kant que «el mantenimiento de la paz social y del estado de derecho» es una coartada recurrente de las tiranías, que típicamente hacen de los fines particulares del tirano y de su clan la condición legal a la que han de someterse los súbditos. Análogamente, un pueblo (incluso un grupo de pueblos) con leyes, no es de suyo un pueblo (o un grupo de pueblos) en una condición civil. Ahora bien, una ley jurídica, para que no se reduzca a una exhortación vacía, conlleva necesariamente la coerción de las conductas de un determinado tipo. De donde surge directamente la pregunta por la legitimidad de la coacción. ${ }^{2}$

3. Es claro hacia dónde se dirige Kant. La coerción arbitraria atenta contra la libertad de los agentes, contra su libertad de escoger, dados ciertos medios y posibilidades, lo que cada cual quiere hacer de sí mismo, y cómo ha de conseguirse la mayor dosis de felicidad según su propio concepto de ella. De modo que la única ecuación en la que la coerción es racionalmente aceptable es aquélla en la cual la restricción a la libertad de cada agente sea compatible con la libertad de todos. Esta es la función del derecho.

El derecho — escribe Kant- es la restricción de la libertad de cada uno a la condición de concordancia con la libertad de todos (...) y el derecho público es el conjunto de leyes externas que hacen posible tal concordancia sin excepción. (T\&P, AA VIII, 289-90)

Erigir una comunidad sobre la base de una constitución ciudadana no significa de suyo para los agentes renunciar a ningún fin particular; significa que si deciden realizar ciertas acciones para lograr sus fines - i.e. las que atenten contra la libertad de otros-, entonces aceptan y están obligados a someterse a sanciones públicamente establecidas. El resultado es que, al tiempo que aceptan el sometimiento a la ley, los agentes se colocan en una situación en la

2 Con Kant, el problema de la legitimidad de un estado histórico podrá o no resolverse de caso en caso, pero supone que previamente se ha respondido a la pregunta (filosófica) por las condiciones en las que es racionalmente aceptable la coerción a las acciones de un cierto tipo. 
que ellos mismos están autorizados a ejercer coerción sobre las acciones de otros, esto es, adquieren derechos civiles.

La condición decisiva para que el derecho pueda cumplir su función constitutiva del estatus civil de una multiplicidad de agentes racionales es la publicidad [Publizität]. Aunque no es posible detenernos en todos los detalles de esta importante pieza de la idea kantiana de sociedad, hay que decir que el autor la toma como un atributo formal (i.e. independiente del contenido) de cualquier demanda de derecho; esto es, para que una pretensión de coartar la libertad de acción de otros sea legal, requiere poder ser públicamente justificada. De ahí se obtiene un antídoto contra cualquier pretensión de coerción que obedezca sólo fines particulares. Kant lo propone como una especie de prueba o examen negativo: si no es posible para un agente (o un grupo de agentes) declarar abiertamente cuáles son las máximas de una acción encaminada a un cierto fin sin frustrar su logro, entonces tal acción es necesariamente contraria al derecho y, por ello, injusta.

Puede afirmarse, finalmente, que la concordia social surgida del contrato original no se caracteriza por la ausencia de conflictos, sino por la manera en que los conflictos pueden dirimirse. El pacto que los agentes racionales emprenden por el pacto mismo constituye, a la manera de un acto fundacional ideal, el pasaje entre una condición social en la que los conflictos se enfrentan mediante la coerción arbitraria - la violencia ciega - y aquella condición, la condición civil, en la que los conflictos se tramitan en un tribunal de justicia pública. De ahí que también pueda afirmarse que el contrato original produce una nueva entidad en el mundo humano, la sociedad de ciudadanos libres - el mundo de la libertad política.

4. Vayamos ahora al célebre pasaje de Hacia la paz perpetua que da título a este trabajo:

Por duro que suene, incluso un pueblo de demonios (siempre y cuando tengan entendimiento) puede resolver el problema de erigir un estado; el problema reza así: «Dada una multitud de seres racionales que requieren leyes universales para su preservación, cada uno de los cuales se inclina en secreto por exceptuarse de ellas, establecer una constitución tal que, aunque ellos se opongan mutuamente en sus actitudes privadas, éstas actitudes se inhiban entre sí de tal manera que su conducta pública sea la misma que si no las tuvieran.» (ZeF AA VIII, 366)

Notemos, de entrada, que cuando el filósofo se refiere en este contexto a un «pueblo de demonios» sometido a la ley civil, no está pensando en cualquier tipo de demonio, sino en un demonio humano. Su peculiaridad es que se trata de un ser con inclinaciones, motivos y pasiones diversas, y, sobre todo, que es radicalmente libre. Lo que esto significa es que la libertad de su arbitrio es la fuente del mal moral, tanto como la del bien. Que alguien sea o se vuelva malo o bueno moralmente, es algo que depende enteramente de él, según adopte en sus máximas de acción determinados incentivos para actuar; y 
es algo que se hace o se ha hecho él mismo, como «efecto de su libre arbitrio» (Rel, AA VI, 44). El punto es importante en virtud de que permite desechar una caricatura generalizada en la recepción de la filosofía moral kantiana, según la cual cuando actuamos moralmente mal estamos causalmente determinados por nuestras inclinaciones naturales. Sólo la libertad humana, y nunca la naturaleza, puede generar el mal. (Ver: Bernstein 2002, 15.)

Tenemos aquí ya una clave para entender el tipo de demonio al que se refiere el pasaje de Hacia la paz perpetua. Se trata, como hemos notado, de un demonio con libre arbitrio; y su carácter maligno consiste básicamente en que supedita los principios a las máximas del amor propio. En realidad esta criatura no necesita ser especialmente perversa, es más bien advenediza, astuta, de conveniencia: su modelo bien podría ser el del tendero que no engaña a la clientela incauta cuando puede hacerlo, no porque sea especialmente honesto, sino porque eso es lo que le conviene hacer para maximizar sus ganancias. Su conducta puede ser, ciertamente, conforme con lo debido, pero ¿qué pasaría si esa misma conducta le reportara más pérdidas que ganancias? Ese tendero actuaría conforme al deber (Pflichtmässig), pero no por deber (aus Pflicht). Pues bien, la idea de establecer una constitución para un pueblo de demonios es la idea de establecer un conjunto de leyes externas que garantice que los ciudadanos, aunque condicionen el deber al amor propio, se comporten como si en la máxima de su acción primara la ley moral en su interior. No importa que sean hipócritas, con tal que cumplan la ley civil.

Veamos esto desde el ángulo de la formulación del imperativo categórico según la máxima de la no instrumentalización. La idea es que, incluso si los miembros de un pueblo albergaran siempre en su interior motivos egoístas, y consideraran a los otros siempre como medios y nunca como fines en sí mismos, un orden civil justo haría posible que su comportamiento público fuera el mismo que si no tuvieran esos motivos e inclinaciones. El incentivo más importante del tendero es egoísta, maximizar su ganancia, y actúa moralmente mal porque condiciona el cumplimiento del deber a la satisfacción de ese incentivo - considera al cliente como un mero medio para enriquecerse. Sin embargo, en tanto que actúa conforme al deber, esto es, en tanto no engaña a la clientela, el tendero es un buen ciudadano. De modo que la sociedad de ciudadanos que Kant propone está formada por agentes que son radicalmente libres, y que se comportan al menos como el tendero, esto es, que si no están dispuestos a actuar por deber, al menos se comporten según el deber.

5. Detengámonos brevemente en el concepto de deber, el cual sin duda pertenece al núcleo de filosofía moral kantiana. En la Fundamentación, la tarea básica de clarificar el principio supremo de la moralidad - el principio por el que actúa un agente racional en la medida en que es moralmente bueno- supone que hay algo así como el deber; esto es, parte de que hay acciones hechas por deber, y su pregunta es cómo es eso posible. Tanto esta obra como la segunda Crítica se ocupan de la moralidad (Sittlichkeit, Moralität) 
más que de la moral (Sitten); su propósito no es dar cuenta de los deberes que tienen los humanos, sino, asumiendo que ellos reconocen deberes prescritos por la ley moral, investigar, primero, el tipo de volición que distingue una acción moralmente buena de una meramente legaliforme, y, segundo, bajo qué condiciones puede prescribirse ese tipo de volición. En un pasaje un tanto críptico, en donde anuncia el cometido de justificar el principio supremo de la moralidad, esto es, que la razón por sí misma puede determinar la acción, el filósofo sugiere que el deber, en tanto ley práctica, involucra «la relación de la voluntad (Wille) consigo misma, en tanto se determina a sí misma sólo por la razón» ( $G r$, AA IV, 63). Kant se percató de que este planteamiento no podía llevarlo a especificar deberes, por lo que promete una futura Metafisica de las costumbres en donde presentará «el sistema completo» de los deberes humanos.

En esta obra, el concepto de libre arbitrio, es de nuevo, la clave del sistema (Ver: $M S$, AA VI, 218n.). Sabemos que, para Kant, el deber no puede derivarse de las inclinaciones naturales de los humanos, sino de su libertad, entendida como su capacidad para elegir entre máximas. Pero, ¿cómo se conecta el deber como relación de la voluntad consigo misma, con la libertad de arbitrio? El deber (Pflicht) contiene dos términos: un sujeto que impone el deber (das verpflichtende Ich), que ejerce coerción, y un sujeto (das verpflichtete Ich) al que se le impone el deber, que es sometido a coerción (MS, AA VI, 419). Las obras canónicas de filosofía moral se ocuparon del primero de estos términos, lo cual es manifiesto en la formulación del imperativo categórico según el principio de autonomía, que presenta a la razón pura práctica como aquella facultad que da la ley moral (gesetzgebende Vermögen). Pero una ley «se da» a alguien, y dar una ley es conectarla con un constreñimiento a realizar lo que manda. El sujeto que se somete a la ley debe ser capaz de satisfacer lo que ella demanda, pero también ha de estar sometido a incentivos que lo pueden llevar a no cumplir la ley. Si recordamos la distinción entre «voluntad» (Wille) y «arbitrio» (Willkür) (Silber 1960, XCV-CVI; Allison 1990, 129 y ss.), podemos elucidar el sentido en el que, para Kant, el deber consiste en una relación de la voluntad consigo misma. El sujeto que impone la ley, i.e. la fuente de la coerción, es el agente en tanto poseedor de voluntad, en el sentido de razón pura práctica, mientras que el sujeto sometido a la ley es ese mismo agente, pero considerado como poseedor de libre arbitrio. Si la razón pura ha de ser razón práctica, debe ser capaz de determinar las acciones; pero sólo puede hacerlo a través de las máximas del agente. Es por eso que, cuando se actúa autónomamente, el deber aparece a la vez como algo impuesto y como algo libremente escogido.

6. Hay en La metafísica de las costumbres un par de distinciones mutuamente relacionadas que conviene ahora introducir. A partir del concepto de libertad, se desprende, según Kant, la diferenciación entre los deberes que conciernen a la libertad externa, y aquéllos que provienen de la libertad inter- 
$n a$, siendo sólo los últimos los que pertenecen propiamente a la ética (MS VI 407). Además, al dividir los deberes en dos sistemas principales, distingue Kant dos elementos en todo dar leyes (Gesetzgebung): una ley, la cual enuncia que algo ha de hacerse, que hace de la acción un deber; y, por otro lado, la coacción (Zwang) sobre el agente que está sujeto a la ley, y que el legislador (quien da la ley) conecta con la ley mediante un incentivo. Este segundo elemento resulta de importancia. Pues si el dador de la ley es externo, esto es, un agente diferente al sujeto de la ley, no puede incluir en la ley los incentivos del sujeto. Esto se debe a que nadie, ni siquiera un posible legislador externo divino, puede prescribir qué incentivos debe tener un sujeto, y nadie sino el sujeto mismo puede decidir cuáles son los incentivos a privilegiar al adoptar la máxima de su acción.

De las consideraciones anteriores surgen para Kant dos nociones claramente diferenciadas de deber, la del civil y la del moral, con su correspondiente sistematización en la doctrina del derecho y la doctrina de la virtud. Así que, aunque el deber moral y el deber civil pueden tener el mismo contenido - por ejemplo, no engañar - se trata de conceptos distintos. Si algo importa en el deber moral, es la máxima y el tipo de incentivo que en ella tiene primacía, esto es, el incentivo racional de cumplir el deber por el deber mismo. Como hemos visto, en cambio, bajo el deber civil la coerción de la ley no puede ejercerse sobre las inclinaciones; pero tampoco requiere del sujeto la adopción de determinadas máximas; lo único que importa para el deber civil es que cualquier máxima que tenga el agente resulte en una acción correcta (gerecht), conforme a derecho. Es por eso que las jurídicas son consideradas por Kant leyes de la libertad externa, leyes que se aplican directamente a las acciones de sujetos radicalmente libres, con independencia de cualesquiera inclinaciones y máximas que ellos puedan tener.

Ahora bien, si esto explica por qué el deber jurídico y el moral son de naturaleza distinta, también permite entender por qué el problema de la legitimidad de la coerción sólo surge en el terreno de la libertad externa. En efecto, si un agente libre reconoce la ley moral dentro pero se inclina por actuar de otro modo, la coacción de la ley se le presentará como algo impuesto, pero siempre como algo que él se impone a sí mismo (§ 6). De donde no parece tener sentido para el agente - siempre en el supuesto de que sea capaz de reconocer la ley moral- preguntarse si la coacción es racionalmente aceptable. Pero en el caso de las leyes de la libertad externa, aunque el agente sea capaz de reconocer, e incluso de hecho reconozca la ley moral, es posible, y hasta probable, que no acepte su coacción. Esto puede deberse a que, desde punto de vista del agente racional autónomo, la ley civil se oponga a la ley moral; o bien a que la ley civil, en concordancia con la ley moral, demande del agente el sacrificio de sus fines particulares. En el primer caso, la ley civil no será considerada justa por el agente - esto es, conforme con el derecho según principios a priori-, por lo cual su asentimiento significaría el sacrificio de 
la autonomía. En el segundo caso, el que realmente interesa ahora, aunque el agente sea en principio capaz de reconocer la ley moral dentro, siempre le será posible preguntarse por qué ha de sacrificar sus fines particulares, y con ello, preguntar si hay una buena razón para someterse a una ley que así se lo pide - la pregunta, en suma, por la legitimidad de la coacción de la ley civil.

7. Desde el punto de vista del contrato original ( $\$ 3$ y 4 ) hay un camino relativamente claro para abordar este problema. Dentro de la condición civil republicana, cuya médula es la publicidad, hay ciertamente espacio para cuestionar si una determinada ley es o no racionalmente aceptable; de hecho, la libertad política, entendida como la libertad para hacer uso público de la propia razón, incluso en asuntos que competen a la legislación misma, es la piedra angular de la obediencia a la ley. En ¿Qué es la Ilustración?, Kant propone al Estado prusiano de Federico el Grande como el ejemplo más brillante de cómo se puede conciliar la libertad irrestricta con la obediencia incondicional a la ley ${ }^{3}$. Independientemente de las motivaciones del filósofo para lisonjear al monarca, aquí expresa su convicción de que sólo es racionalmente aceptable someterse a la coerción de una ley jurídica a condición de que se le pueda criticar abiertamente y, según sea el caso, modificar o cancelar.

Así, pues, un agente al que la ley le pide sacrificar determinados fines particulares, aunque puede en efecto disentir de ella y criticarla, no puede rehusarse a obedecer, so pena de ser sancionado. Es notorio que la situación genera un sesgo en la carga de la prueba por parte del disidente: independientemente de sus motivaciones profundas - si le mueve la buena voluntad, la filantropía o la avaricia - es él quien tendrá que demostrar, en la arena pública, que la ley en cuestión es inaceptable; que, en realidad, ella sólo es expresión de los fines privados de una persona o grupo, o que sería imposible que la comunidad entera (ein Volk) asintiera a ella. ${ }^{4}$ Entretanto, hay que suponer que la ley salvaguarda la libertad de cada cual y es válida para todos los agentes.

Independientemente de que nos ofrezca una imagen conservadora o al menos ralentizada de los cambios políticos, el punto de vista de una constitución civil republicana emanada de la idea de contrato social proporciona una explicación de la legitimidad de la ley civil para coartar determinadas acciones. La autoridad establecida, por lo tanto, puede usar todo su poder para obligar, especialmente a los demonios con entendimiento, a cumplir con la ley.

8. Aquí llegamos al punto crítico del planteamiento kantiano. Como hemos visto (\$4), los demonios con entendimiento son agentes radicalmente libres que sistemáticamente subordinan la ley moral al amor propio y que, por tanto, tienden con sus acciones a instrumentalizar a otros agentes. Por otro

${ }^{3} C f r$. WA, AA VIII, 41: «Sólo un gobernante puede decir: "argumenta todo lo que quieras y sobre lo que quieras, pero obedece."»

${ }^{4}$ La diferencia de formulaciones en WA, AA VIII, 38-9 y T\&P, AA VIII, 297n., tiene que ver, presumiblemente, con el tipo de ejemplo que Kant utiliza en ambos casos. 
lado, como acabamos de plantear, de la idea de contrato original se extraen las condiciones bajo las cuales es en todo caso legítimo coartar las acciones de estos demonios - aquéllas que atenten contra la libertad de los demás. Pero de ello no se sigue, al menos claramente, que los demonios con entendimiento puedan - menos aún que deban - pactar un contrato original.

Veamos esto desde el ángulo de las diferencias que hasta el momento es posible trazar entre la acción moral y la acción política. De La metafísica de las costumbres ( $(6)$ es posible extraer la idea de que en ambos casos se trata de la misma acción, y que la diferencia estriba en el principio que rige la obligatoriedad de la ley o, si se quiere, en la fuente de la coerción. En el primer caso, la ley moral se presenta como un mandato - un imperativo - para seres que, si bien son capaces de autodeterminación, tienen la posibilidad, y a menudo la toman, de actuar de otra manera. La fuente de la coerción es en este caso la propia conciencia del agente: su reconocimiento de la ley moral dentro; y la coerción además se ejerce sobre las máximas del agente o, mejor, sobre su tentación permanente a priorizar las máximas del amor propio sobre las máximas del deber. En el segundo caso, como ya se ha visto, nada de esto es necesario: a la ley civil no le incumben las máximas ni las creencias profundas de los agentes, y se dirige, por así decirlo, al ejercicio de sus decisiones prácticas, a su comportamiento públicamente observable. En consecuencia, la acción política resulta independiente de la acción moral, en el sentido en que el agente no requiere actuar moralmente bien para cumplir con el deber civil, para ser un buen ciudadano. Esto explica que, en la condición civil, incluso los agentes que sistemáticamente buscan con sus máximas instrumentalizar a los demás están obligados a actuar en conformidad con la ley (Castillo 2004, 217).

Si éste es el significado de la metáfora de los demonios con entendimiento, entonces todo parece encajar adecuadamente con lo dicho hasta ahora. No obstante, la idea de que el problema de establecer una constitución ciudadana - en esencia, el problema de adquirir o lograr una condición civil— puede ser resuelto por demonios sugiere que la metáfora tiene mayores pretensiones. Que un pueblo de demonios sea capaz de resolver lo que la Idea denomina el problema más difícil para la especie humana (Idee, AA VIII, 22), sugiere que, para la instauración misma de la condición civil, para pactar un contrato original, no se requiere de los agentes que actúen de hecho por deber, basta que tengan entendimiento suficiente para ajustar medios a fines. Aquí se nos pinta una imagen muy diferente de las diferencias entre la moral y la política, a saber, que no se requiere el punto de vista moral de la acción, para que esa acción pueda ser en general sancionable por la ley civil según principios a priori; en suma, que no se requiere el punto de vista moral para lograr o adquirir una condición civil republicana. Esto, sin embargo, es algo que hasta ahora no ha sido argumentado y es, como lo considero, en última instancia insostenible con las piezas de las que Kant mismo dispone. 
9. Evaluemos pues, ahora, la idea de que un pueblo de demonios puede lograr organizarse según las leyes de la libertad política. Hay que recordar, de entrada, que Kant introduce su metáfora del pueblo de demonios para contrastarla con un pueblo de ángeles, y se propone responder a quien objete que su idea de sociedad sólo es aplicable para agentes que nunca priorizan sus fines personales sobre la ley moral. De ahí el enfático, «incluso un pueblo de demonios» puede lograr la hazaña de erigir una constitución republicana. Pero, ¿cómo es eso posible? ¿Cómo es que un pueblo de criaturas infinitamente astutas, que jamás siguen otra ley que la de sus fines particulares, puede lograr una sociedad «tan sublime»?

En Hacia la paz perpetua, la respuesta de Kant tiene el estatuto de una garantía: el género humano goza de una suerte de patente de corso provista, en su sabiduría, por la naturaleza. Estamos de lleno en el terreno del relato teleológico, el cual se puede encapsular bien con dos citas de la literatura latina, entre las muchas con las que el autor adereza sus textos: Ducunt volentem fata, nolentem trahunt ${ }^{5}$, y Natura daedala rerum ${ }^{6}$. En efecto, según este relato, la naturaleza, entendida como una totalidad organizada según fines, «interviene» en la marcha de la historia humana para producir concordia, justamente mediante la discordia característica de las relaciones entre los individuos y los grupos de la especie. En una nota el filósofo insinúa el sentido de esta intervención: ahí donde se ve la huella de un diseño según un plan, ahí se habla comúnmente de «providencia divina», por más que la modestia teórica de la razón humana sugiera hablar en términos de la naturaleza teleológicamente concebida. Hay, no obstante, varias maneras de entender la noción de «providencia» (Vorsehung):

en cuanto se coloca en el comienzo de los tiempos es providencia fundadora (providentia conditrix)...; en cuanto conserva el curso de la naturaleza según leyes universales de la finalidad, es providencia rectora (providentia gubernatrix); en cuanto realiza fines particulares que las personas no podrían haber previsto, y cuya existencia sólo se puede sospechar por el resultado, es considerada providencia conductora (providentia directrix); finalmente, si algunos acontecimientos particulares son considerados como fines divinos, no hablamos más de providencia sino de una dispensa (directio extraordinaria). (ZeF, AA VIII, 361n.)

Pues bien, la naturaleza, concebida como un sistema de fines, tiene todas las características que le adjudica aquí Kant a la providencia, de modo que no

5 «Los destinos conducen al que quiere, y arrastran al que no quiere.» Séneca, Epístola 107, citado en $T \& P$, AA VIII, 313.

6 «La naturaleza, hacedora de la cosas.» Lucrecio, De rerum naturae, V, citado en $\mathrm{ZeF}$, AA VIII, 360. 
interviene en los acontecimientos humanos de manera caprichosa y ocasional - no se trata pues de una intervención milagrosa; en tanto que criaturas vivas, los humanos siguen el diseño que la naturaleza le da a la especie y, en ese sentido, se trata de un arreglo teleológico fundador- que opera conjeturalmente desde el inicio de la historia humana; pero este arreglo también sostiene el curso de los acontecimientos y sobre todo les da una dirección que los agentes, siguiendo sus fines particulares, no habían previsto; esa dirección, en última instancia, no es otra que la de una sociedad cosmopolita de ciudadanos libres.

Como se sabe, el mecanismo del que se sirve la naturaleza para lograr este fin, es lo que en la Idea llama Kant la insociable sociabilidad, el antagonismo estructural entre los individuos y los grupos de una especie que requiere cooperar para prevalecer. Aquí hace su aparición la llamada astucia de la naturaleza (Arendt 1982, 16; Yovel 1980, 277), pues justamente al perseguir sus fines particulares -inclusive mediante el uso indiscriminado de la violencia- los individuos promueven, sin proponérselo, un fin superior, esto es, el de la constitución de un pueblo en una sociedad de ciudadanos, y el de la conformación de una federación de repúblicas libres. Lo crucial sin embargo es que en el relato teleológico la naturaleza se queda siempre un paso antes de lo que se requiere para pactar un contrato original y transitar hacia la paz perpetua. En efecto, para entrar en un pacto por el pacto mismo, independientemente de motivaciones y fines particulares, los agentes requieren la capacidad de autodeterminarse, de hacer del deber el fundamento de determinación de la voluntad; en suma, requieren el punto de vista de la razón práctica. Pero la naturaleza teleológicamente concebida no puede producir tal capacidad en los individuos humanos. Lo más que puede hacer es preparar el terreno, según se colige de la versión más acabada de este relato, a saber, la de la última parte de la Crítica del discernimiento. ${ }^{7}$

7 La tercera Crítica, recordemos, se propone validar el modo de pensar teleológico en el sistema crítico. Más aún, la Metodología del discernimiento teleológico retoma y enriquece las preocupaciones centrales de la filosofía kantiana de la historia. Ahí, el autor supone la solución a la antinomia del discernimiento, según la cual es posible juzgar sin contradicción ciertos fenómenos en términos tanto de causas eficientes como de causas finales (§§ 72-73). Kant piensa aquí en aquellos fenómenos - individuos en espacio y tiempo-que pueden ser considerados como formas naturales o seres organizados. El argumento rector es entonces heurístico: para entender la existencia misma de ciertas formas naturales debemos asumir un diseño según fines. Como lo pone dramáticamente el propio Kant, es imposible concebir incluso una brizna de pasto «en términos de leyes naturales que no están ordenadas según una intención» [§ 75]. La solución está prefigurada en la introducción a la tercera Crítica [IV], pues, en último término, mediante el principio de la finalidad no conocemos objetivamente la naturaleza; la teleología, como lo expresa Kant, es una condición subjetiva para el juicio reflexionante, no para el determinante (Ver: Mendiola 1999, 82ss; Guyer 1996, 52 y ss). Así, desde el punto de vista teleológico, cada ser natural puede representarse como un fin externo, en tanto puede verse como un medio para lograr un determinado propósito. La naturaleza como un todo puede ser representada entonces a la manera de un sistema de seres organiza- 
10. Como se recordará, en la Metodología del discernimiento teleológico la historia natural toma un giro específicamente humano. Si ha de pensarse a la naturaleza como un sistema completo de fines externos, ésta debe contener, según Kant, un fin que a su vez no esté condicionado por otro, un último miembro de la serie en la cadena de fines naturales. Esto sólo sucede con los individuos de una especie natural, la humana. Las criaturas de otras especies son ciertamente capaces de seguir fines, incluso de colaborar para un fin común (como las abejas y los castores); pero sólo la criatura humana es capaz de representar fines para los cuales ha de utilizar a la naturaleza y sus productos como medios. El punto crucial es la distinción antropológica que traza Kant entre fin último [lätzter Zweck] y fin final [Endzweck] de la naturaleza $[K U \S \S 82$ y 83]. Brevemente, el ser humano, tomado como especie natural, es el fin último de la naturaleza en la medida en que puede ubicarse en la posición superior en la cadena de los seres vivos, pero es el fin final de la naturaleza en tanto capaz de plantearse fines que la naturaleza no puede darle. Lo peculiar de la ecuación kantiana es que lo último es condición de lo primero: para ocupar una posición privilegiada en la cadena de las causas finales naturales, el ser humano requiere poder escoger fines. Sólo es fin último en tanto que fin final de la naturaleza (Villacañas 1990, 45 y ss.).

En $K U \S 83$, Kant plantea la pregunta acerca de la contribución de la naturaleza a la historia humana — ¿qué es aquello que en el ser humano mismo debe promoverse como fin mediante su conexión con la naturaleza? Inmediatamente enuncia dos opciones. O bien lo que es un fin en el ser humano mismo es tal que la naturaleza misma en su magnanimidad puede proveerlo, esto es, la felicidad; o bien el fin es la aptitud y destreza humana para plantearse y conseguir fines, esto es, la cultura [Kultur]. El argumento de Kant para eliminar la primera opción es conocido: el concepto de felicidad es tan cambiante y multiforme que nada estable puede con él lograrse en el terreno de la acción según fines ( $G r$, AA IV, 395-96). En el marco del discernimiento teleológico, el argumento toma un giro peculiar, a saber, si los humanos sólo fueran capaces de plantearse fines según su propio concepto de felicidad, entonces la especie no dejaría de ser un mero medio en la cadena natural de causas finales, con lo cual nunca podría ser considerada fin último de la naturaleza. En efecto, es debido a que el individuo humano es capaz de escoger los fines de sus acciones, esto es, debido a su libertad de arbitrio, que el humano puede elevarse sobre el resto de las criaturas naturales y ser considerado el último eslabón en la cadena de los fines de la naturaleza. Puesto que sus fines no son dados, esto es, la naturaleza no los provee de suyo, el individuo humano ha de probarse y desarrollar sus capacidades racionales, su entendimiento e imaginación, para hallar los mejores medios en vista de sus fines. Desde el punto

dos en géneros, cada uno de los cuales, en tanto existe para otros, puede ser considerado como un fin externo. 
de vista de la especie, la cultura es el fruto de las capacidades intelectuales humanas, probadas repetidamente frente a adversidades y riesgos de todo tipo. Hay dos vías por las que la naturaleza contribuye a la condición en la cual la criatura humana puede considerarse fin último de la naturaleza: la cultura de la destreza (Geschichtlichkeit) y la de la disciplina (Zucht). Sin la destreza, una disposición natural en los humanos, la aptitud para fines permanece vacía, en tanto los agentes se muestran incapaces de lograr, en los hechos, sus fines. El desarrollo de la destreza, no obstante, lleva irremediablemente a la desigualdad, a la «miseria reluciente» $\mathrm{y}$, en última instancia, a la violencia, a las guerras internas y externas. La cultura de la disciplina, por su parte, permite minimizar la interferencia de las inclinaciones naturales de los agentes con el desarrollo de su humanidad, y deshacerse de la «tiranía de la propensión sensible».

Lo fundamental aquí es que la naturaleza, en tanto sistema de fines, no produce su propio fin último; haciendo de la violencia y la guerra un acicate para el desarrollo de la destreza y la disciplina en los individuos, la naturaleza contribuye a la formación de la especie como su fin último. No obstante, para que la cultura humana pueda ser considerada como el fin último de la naturaleza, se requiere una condición que la naturaleza misma no puede proveer, esto es, que el ser humano «entienda y tenga la voluntad de darle a la naturaleza y de darse a sí mismo una relación con un fin que pueda ser independiente de la naturaleza, suficiente por sí mismo, esto es, un fin final; un fin que, sin embargo, no debe buscarse en la naturaleza» ( $K U$ § 83; AA V, 431). En este pasaje y en el siguiente, queda claro que Kant está pensando en la condición de fin final de la especie como la condición moral: «sólo en el ser humano, y en éste sólo como sujeto de la moralidad, ha de encontrarse aquella legislación incondicionada en relación con fines que lo hace sólo a él capaz de ser un fin final, bajo el cual la naturaleza toda se ordena teleológicamente.» ( $K U$ §84, AA V, 435).

Como se aprecia, la naturaleza sólo puede conseguir formar a los individuos de la especie en la cultura de la destreza y de la disciplina; pero permanece muda acerca de la determinación y selección de los fines que ellos persiguen. Para eso se requiere el punto de vista de la razón práctica, el punto de vista del deber moral. La naturaleza, siempre teleológicamente concebida, hace de las criaturas humanas agentes, individuos que persiguen fines, pero no los hace capaces de darse a sí mismos la ley que determina sus acciones. Es por eso que, en este marco, tiene pleno sentido que, primero, la sociedad civil bajo una constitución republicana y, después, un sistema cosmopolita de Estados «sobre bases morales», se cuenten como «condiciones formales» para que la especie alcance el estatuto de fin final de la naturaleza. Pero si, para tornarse fin final, el humano requiere adoptar la condición civil, entonces es claro que la naturaleza por sí misma no logra que las tendencias antagónicas de los agentes se neutralicen mutuamente. Desde el ángulo de la te- 
leología, entonces, el pacto por el pacto mismo es un salto mortale que la naturaleza misma no puede dar. Para ello se requiere, según el texto que seguimos, no sólo de astucia, sino sobre todo de sabiduría; o, más claramente, como lo pone Kant en la Idea (AA VIII, 23), una dosis de experiencia en los asuntos del mundo y, ante todo, buena voluntad.

11. Veamos esto desde otro ángulo. La $K U$ y la Idea sugieren una narración conjetural en varias etapas o fases del proceso de humanización de ese peculiar ser natural capaz de plantearse y escoger fines. Brevemente, la primera fase es la de la «libertad sin ley», en la que cada individuo y cada grupo persiguen sólo sus fines particulares. La segunda es la fase en la que los agentes están sometidos a una legislación externa, el estado o condición que Kant llama de la justicia natural (natürliche Gerechtigkeit); la tercera es la de la sociedad de ciudadanos organizada según principios republicanos; finalmente, se halla la fase de la paz perpetua - de la libertad bajo principios a priori del derecho cosmopolita. Pues bien, ¿hasta dónde llega en este decurso el «mecanismo de la naturaleza»? Según Hacia la paz perpetua, la naturaleza puede llevar a la especie de la primera a la segunda fases. En efecto, en la fase de la libertad sin ley, los individuos, y los grupos, se hallan permanentemente sujetos a las depredaciones de los otros, de modo que constantemente están frente a la posibilidad de ser o bien víctimas, o bien verdugos (Höffe 1988, 63; Laberge 2004, 162). Eventualmente se percatan de que el mejor camino no sólo para maximizar el logro de sus propios fines sino para evitar ser víctimas, es actuar conforme a ciertas leyes a todos aplicables, esto es, adoptar el estado de la justicia natural. Aquí los agentes no requieren más que la sagacidad y seguir sus propios fines para percatarse de que lo que más les conviene es cooperar y coaligarse con otros - es por eso que «demonios con entendimiento» es una expresión apta para designarlos. Esto significa que, dotados con tales capacidades, estos agentes pueden remontar lo que se ha llamado el estado de naturaleza primario (O’Neill 1989, 208). En otros términos, un pueblo de criaturas infinitamente astutas, que jamás siguen otra ley que la de sus fines particulares, puede lograr un pacto mediante el cual establezca leyes que regulen las relaciones entre ellas. La razón básica de ello es que una evaluación de la mejor estrategia para maximizar sus fines llevará a estos agentes a someterse a la autoridad de la ley.

Esta manera de entender el relato teleológico explica en efecto que los agentes sean capaces de establecer un pacto mutuamente conveniente. Aunque esta situación significa ciertamente un avance en relación con el estado de naturaleza primario, y aunque es aquí donde los agentes se vuelven diestros y disciplinados para conseguir sus fines, ella resulta del todo precaria e inestable. La naturaleza, «la propensión hacia la animalidad», sigue haciendo sentir sus efectos sobre los individuos y los pueblos. Por un lado, en el terreno local, subsiste la amenaza permanente de disolución y guerra interna; por otro, en el ámbito foráneo, las diferencias lingüísticas y religiosas y el inter- 
cambio de bienes (ZeF, AA VIII, 367-68), conducen al enfrentamiento y a las guerras entre los pueblos. Lo importante aquí, para nuestro problema, es que si se concibe a los agentes como demonios con entendimiento, para ellos vale que prefieren la cooperación general a la depredación generalizada, pero también que preferirían aún más un acuerdo del cual se pudieran sustraer unilateralmente. Desde el punto de vista de la maximización de sus fines particulares, que es el único que ellos adoptan, la mejor ecuación para los demonios con entendimiento, preferible incluso a la de la libertad en el estado de naturaleza primario, es el estado de impunidad: la libertad irrestricta para sí, la coacción civil para los otros. En último término, ese es el caldo en el que se cocinan sucesivamente las tiranías y las revoluciones.

Es claro que un pacto de este tipo dista mucho de garantizar una unión de ciudadanos bajo una constitución republicana y, en esa medida, no conduce al género humano hacia la paz perpetua. Esto se debe a que el mecanismo de la naturaleza por sí mismo logra sólo una concordia endeble y pasajera, que no le permite a los agentes disfrutar de la libertad bajo leyes. Puesto que el motor del pacto son los fines particulares de los agentes, el pacto mismo resulta un medio para maximizar esos fines, de modo que cuando por alguna causa éstos no se consiguen — cuando, por ejemplo, la seguridad no está garantizadadeja de existir en los agentes una motivación para seguir el pacto. Para lograr que la concordia perdure, los demonios tendrían que aceptar la espada de la justicia, una condición en la que se garantice que los perjuicios de no cumplir la ley sean mayores que los beneficios. Pero, incluso si ellos se ponen de acuerdo sobre el contenido de las leyes, sus pesos y contrapesos, ¿a cuál de los demonios podría confiársele la espada? Harto saben ellos qué destino tendría el arma en manos de uno (o de un grupo) de sus congéneres. El asunto está planteado con toda claridad en la Idea: El ser humano tiende a considerarse arbitrariamente como una excepción y, por ello, «es un animal que, cuando vive entre otros de su mismo género, necesita un señor» Pero, «¿de dónde extrae él este señor? De ningún lugar sino del género humano; pero éste es igualmente un animal que necesita un señor» (AA VIII, 23). La disyuntiva relevante está sugerida en la Doctrina del derecho (MS, AA VI, 341): la ley o bien rige por sí misma [das Gesetz ist selbstherrschend], o bien depende de una persona particular. En éste último caso el problema se renueva, pues esta persona será, también, una criatura que necesita un señor. El primero, donde la ley no depende de una persona particular, supone de los agentes buena voluntad, algo que los demonios con entendimiento simplemente no poseen. 
12. Consideremos ahora algunas conclusiones. Según la Idea y la tercera Crítica, un pacto entre demonios con entendimiento no resuelve el problema de cómo adquirir la condición civil, aquélla en la que la libertad irrestricta coexiste con la mayor autoridad y la mayor fuerza de la ley; y, consiguientemente, carece de recursos para resolver el problema de la legitimidad de la coerción civil (§ 7). En otros términos, el paso de la segunda a la tercera y cuarta fases del proceso mencionado $(\S 11)$ requiere un salto cualitativo en las capacidades de los agentes, un salto que la naturaleza no puede dar. Es por eso que tiene pleno sentido, en la formulación de Teoría y práctica $(\S 2)$, que el contrato social se plantee como «un deber primordial e incondicional», como una especie de imperativo categórico histórico-político. En efecto, entrar en un pacto por el pacto mismo sólo puede plantearse como un mandato para aquellos agentes que no sólo son aptos para ajustar los mejores medios para sus fines, sino que también reconocen deberes y, al menos en ocasiones, son capaces de actuar por deber. Estos son agentes simplemente humanos, que a veces actúan por deber, a veces sólo según el deber, y a veces de plano en contra del deber. Esto significa, efectivamente, que los agentes requieren capacidades morales para contraer un pacto con las características que Kant le adjudica a la sociedad de ciudadanos. Pero, como hemos visto (§ 8), de ahí no se sigue que los agentes pacten ser buenas personas, sino actuar al menos según la ley. Pues bien, ¿en dónde deja esto la afirmación, en Hacia la paz perpetua, de que incluso demonios con entendimiento pueden resolver el problema de erigir un Estado? Si «erigir un Estado» [Staatserrichtung] quiere decir establecer una sociedad bajo una constitución republicana que garantice la libertad política, entonces es claro por lo visto que tal afirmación carece de fundamento.

Esto deja dos alternativas de reinterpretación del pasaje: o bien que los demonios con entendimiento pueden establecer un pacto determinado por la maximización de sus fines particulares, o bien, que, una vez establecida la condición civil de los agentes, incluso demonios con entendimiento pueden neutralizar, mediante la ley, las tendencias humanas al antagonismo, esto es resolver el problema de qué penas corresponden a qué faltas. La primera opción $(§ 11)$ se traduce en la idea de que incluso autómatas del autointerés pueden remontar el estado primario de naturaleza. Es preciso recordar, no obstante, que en este caso la ley depende de una persona y no manda por sí misma. La segunda opción significa que la ley ya manda por sí misma, y sugiere que el problema al que se refiere Kant es específicamente jurídico (Labergue 2004, 164), por lo cual su solución no requiere de capacidades morales. Esto arroja como consecuencia interpretativa que, una vez que se ha descartado que demonios con entendimiento puedan erigir una constitución republicana, ambas opciones se presentan como las únicas vías posibles para 
conciliar los textos de la Idea y la Metodología del discernimiento, por un lado, con los de Hacia la paz perpetua, por otro.

13. Más importante, sin embargo, si lo que hemos venido diciendo es correcto, es que las tensiones internas de la idea kantiana de sociedad sólo parecen atenuarse con un particular sesgo, a saber, enfatizando la tesis de la moralización de la política y el relato trascendental frente a la tesis de la independencia de la política respecto de la moral y el relato teleológico. El relato trascendental, como sabemos, está dirigido a establecer las condiciones normativas bajo las cuales es posible la concordia social. Su médula es el principio de la publicidad del derecho (§3), el cual está diseñado para evitar aquellas acciones que instrumentalizan a los demás, al tiempo que garantiza la libertad de cada cual para buscar sus propios fines. En esa medida, puede afirmarse que la idea de contrato social es la expresión política de eso que en otra parte llama Kant «el reino de los fines». Como sabemos, esta idea supone que los agentes son radicalmente libres, pero también, y sobre todo, racionales: capaces de autodeterminación y, por tanto, capaces de considerar a los demás no sólo como medios, sino también, y sobre todo, como fines en sí mismos. Es esta la única condición bajo la cual los agentes pueden disfrutar de la libertad política (la libertad para usar públicamente su razón), y en la que la coerción legal tiene plena legitimidad (§7). Que los agentes no ejerzan siempre y en todos los casos tales capacidades no afecta en absoluto su validez y el contenido práctico del contrato social en tanto que idea de la razón. Es por eso que el relato trascendental desemboca en la tesis de que la política sólo puede ser acción según principios dentro de los límites de la razón práctica. Esta es, para Kant, la única vía para romper el ciclo repetitivo de tiranías y revoluciones.

Uno puede dejarse seducir por el relato teleológico, y aceptar acríticamente que, tal y como lo presenta Kant en algunos pasajes, éste converge con el relato trascendental; es decir, que, por su propia evolución, el antagonismo estructural entre los individuos y los grupos humanos lleva a la especie a la situación en el que el máximo de libertad individual convive con el máximo de cooperación social. Hemos argumentado que esto es incorrecto. Simplemente no hay paso directo posible entre la historia natural (o meramente mecánica), en donde prevalece el autointerés depredador, y la historia racional, en donde lo que prevalece es la acción realizada por deber (Yovel 1980, 21 y ss.). Esto conduce al siguiente $\mathrm{y}$, tal vez, paradójico resultado: si la historia natural, por más que evolucione, sigue siendo siempre historia natural, ello significa que, bajo el relato teleológico, la acción política no puede ser sistemáticamente independiente de la moral. Esto se debe a que, puesto que aquí la ley no manda por sí misma, nada garantiza que su fuerza coercitiva se dirija sólo hacia lo que las personas en efecto hacen, y nunca hacia lo que creen - hacia sus máximas de acción. De modo que la política sólo puede ser entonces independiente de la moral, a condición de que los sujetos de la acción sean agentes morales, capaces de hacer algo más con sus congéneres que instrumentalizarlos. 


\section{BIBLIOGRAFÍA}

1. KANT, I. Las obras de este autor se citan según la paginación de la edición de la Academia (AA): Kants Gesammelte Schriften, Berlín, Königlich Preussische Akademie der Wissenschaften, 1908-13. Las referencias corresponden a las abreviaturas enlistadas, seguidas por la indicación del tomo y la página. Con excepciones, las citas siguen las traducciones españolas indicadas entre corchetes.

Gr Grundlegung zur Metaphysik der Sitten (1785), AA IV, 387-463. [Fundamentación de la metafísica de las costumbres, traducción de J. Mardomingo, Barcelona, Ariel, 1996]

Idee Idee zu einer allgemeinen Geschichte in weltbürgerlicher Absicht (1784), AA VIII, 17-31.[Idea para una historia en clave cosmopolita y otros escritos sobre filosofía de la historia, traducción de Concha Roldán y Roberto R. Aramayo, Madrid, Tecnos, 1987.]

KU Kritik der Urteilskraft (1790), AA V, 167-485. [Crítica del discernimiento, traducción y edición de Roberto R. Aramayo y Salvador Mas, Madrid: A. Machado, 2003]

MS Die Metaphysik der Sitten (1797), AA VI, 205-492. [La metafísica de las costumbres, traducción de Adela Cortina y Jesús Conill, Madrid, Tecnos, 1989.]

Rel Die Religion innerhalb der Grenzen der bloßen Vernunft (1793), AA VI, 13-197. [La religión dentro de los límites de la mera razón, traducción de Felipe Martínez Marzoa Madrid, Alianza, 1981.

T\&P Über den Gemeinspruch: Das mag in der Theorie richtig sein, taugt aber nicht für die Praxis (1793), AA VIII, 275-313. [Teoría y práctica, traducción de J. Miguel Palacios, M. Francisco Pérez López y Roberto R. Aramayo, Madrid, Tecnos, 1986]

WA Beantwortung der Frage: Was ist Aufklärung? (1784), AA VIII, 35-42. [¿Qué es la Ilustración, traducción de Agapito Mestre y José Romagosa, Madrid, Tecnos, 1989]

ZeF Zum ewigen Frieden (1795), AA VIII, 343-386. [Hacia la paz perpetua, traducción de Joaquín Abellán, Madrid, Tecnos, 1998.]

\section{Referencias}

Allison, Henry (1990): Kant's Theory of Freedom. Cambridge, RU, CUP.

Arendt, Hannah (1982): Lectures on Kant's Political Philosophy, Chicago, The University of Chicago Press.

BernsteIn, Richard (2002): «Radical Evil: Kant at War With Himself», en: Radical Evil: A Philosophical Interrogation, Cambridge, pp. 11-45.

Castillo, Monique 2004: «Moral und Politik: Misshelligkeit und Einhelligkeit» en HÖFFE (ed.), pp. 195-220.

GuYer, Paul (1996): «Los principios del juicio reflexivo», en Diánoia XLII-42, pp. $1-60$.

HöFFE, Otfried (1988): Der Staat braucht selbst ein Volk von Teufeln. Stuttgart, Reclam.

— (ed.) (2004): Immanuel Kant: Zum ewigen Frieden, Berlin: Akademie. 
Laberge, Pierre (2004): «Von der Garantie des ewigen Friedens», en Höffe (ed.), pp. 149-170.

RIEDEL, Manfred (1981): «Transcendental Politics? Political Legitimacy and the Concept of Civil Society in Kant», en: Social Research 48-3, pp. 588-613.

Mendiola, Carlos (1999): «Acerca de la distinción entre la capacidad de juzgar reflexionante y determinante en Kant.» Theoría, 8-9, pp. 79-99.

O’NeILl, Onora (1989): Constructions of Reason. Explorations of Kant's Practical Philosophy, Cambridge, Cambridge University Press.

SILBER, John 1960: «The Ethical Significance of Kant's Religion», en Kant, Religion within the Limits of Reason Alone, Nueva York, Harper: 1xxix-cxxxiv.

VILlaCAÑas, José Luis (1990): «Naturaleza y razón: Kant filósofo del clasicismo», en VV.AA., Estudios sobre la Crítica del Juicio, Madrid, CSIC/Visor, pp. 13-74.

Yovel, Yirmiyahu (1980): Kant and the Philosophy of History. Princeton: Princeton University Press. 